\title{
La filosofía sin más ni menos*
}

\section{Adolfo Sánchez Vázquez}

\begin{abstract}
I
$\mathbf{E}$

n nuestra conferencia nos proponemos aportar algunas reflexiones a un tema tan venerable como la filosofía misma: el de la naturaleza de esta actividad que el hombre practica desde hace aproximadamente veintisiete siglos, si tomamos como acta de nacimiento el pensamiento de los primeros filósofos griegos. Partimos de la idea, con base en su propia historia, de que se trata de una actividad intelectual específica que se distingue de la magia, el mito, la religión, el arte, la ciencia, la política u otras formas del comportamiento teórico o práctico humano. Se trata, en consecuencia, de un quehacer que, por su carácter específico, no ejercen todos los hombres, sino aquéllos que, distinguiéndolos de otros, llamamos filósofos. Lo cual no significa que el modo de darse haya sido siempre el mismo, o idéntico a la forma profesional con que se presenta apenas desde hace dos siglos, con su espacio propio, en las instituciones académicas. El ejemplo paradigmático del filosofar en el pasado, fuera de la academia, es el filósofo callejero Sócrates, no sólo porque es en la calle donde filosofa, sino porque es en ella, o a la vuelta de la esquina, donde encuentra a sus discípulos o interlocutores. En tiempos modernos y contemporáneos, baste citar los nombres de Kierkegaard, Schopenhauer, Feuerbach, Marx, Gramsci o Sartre, como ejemplos de un filosofar extraacadémico que, no por ello dejan de tener un puesto asegurado en la historia de la filosofia. $Y$ lo que los mantiene en ella es el tipo de problemas que abordan, el modo de abordarlos y la inquietud que, frente a las creencias aceptadas, siembran sus respuestas.

No obstante, la diversidad de las filosofias, a lo largo de su historia, en cuanto a los problemas planteados, las vías de acceso a ellos y las
\end{abstract}

- Conferencia pronunciada en la Facultad de Filosofía y'Letras de la unam el 21 de enero de 1992. 
conclusiones a que llegan al abordarlos, puede afirmarse que todas ellas se mueven en sus reflexiones en dos planos conceptuales, mutuamente vinculados entre sí: el de la relación del hombre con el mundo, y el de las relaciones de los hombres entre si, pero, a su vez, en un tercero: el del conocimiento con que se examinan esas relaciones. En cierto modo, ha sido Kant quien ha trazado el terreno que suele cultivar el filósofo, al ponerlo en relación con cuatro preguntas fundamentales: la primera, "¿qué puedo conocer?", tiene que ver con el conocimiento del mundo con el que el hombre se halla en relación; la segunda, “qué debo hacer?", apunta al comportamiento práctico humano (aunque limitado por Kant a la esfera de la moral); la tercera, "¿qué me es dado esperar?", interroga sobre lo que el futuro puede traer al hombre, $y$, finalmente, todas estas preguntas remiten a una cuarta, más radical, “'qué es el hombre?”, acerca de la naturaleza del sujeto que conoce, que se comporta prácticamente y que espera algo que no se da en su presente. Y ese sujeto - el mismo en el conocimiento, en la moral y en la espera, o esperanza, de lo que no es todavia-es el hombre.

\section{II}

Nos aproximamos así a una caracterización de la filosofía, propia sobre todo de la época moderna y contemporánea, que tiene su centro o su raíz en el hombre, en cuanto sujeto y objeto de ella. Una filosofía con dos grandes referentes - la naturaleza y la sociedad-que lo son, a su vez, - vinculados entre sí- de la vida humana. Se trata de una actividad teórica interesada, ya que la guía el interés vital del hombre por esclarecer su puesto y su comportamiento en relación con esos referentes de su existencia. Estamos, pues, ante un saber interesado por responder a ese interés vital que no es exclusivo del filósofo. También lo experimenta el nofilósofo, el hombre de la calle con el que dialogaba Sócrates, o el proletario que tenía en mente Marx, y que buscan respuesta propia con ayuda del "sentido común", o de una "prefilosofia", o "filosofia para andar por casa".

Ahora bien, si la filosofia aspira a esclarecer el lugar del hombre en el mundo (con su doble referencia natural y social), es porque no se siente seguro, firme o tranquilo en él. La inseguridad, la perplejidad o inconformidad testimonian una relación humana incierta de la que se hace eco la filosofía. Entender el mundo se hace necesario para poder orientarse en él con cierta seguridad, certeza o armonia. Y puesto que esta búsqueda es interesada, la expresión filosófica correspondiente no puede desprenderse de la posición humana, social, que, en una situación histórica determinada, genera el interés vital correspondiente. Así pues, la actividad 
filosófica de un sujeto que se tiene a sí mismo por objeto, como actividad interesada tiene siempre cierto componente ideológico. Y, en este sentido, no hay filosofia pura, inocente, o neutra ideológicamente.

La seguridad, confianza o certidumbre que busca la filosofia, no permite afirmar que siempre la alcance. Por el contrario, puede elevar aún más la inseguridad, perplejidad o incertidumbre. Y ello sin dejar de ser, o justamente por ser una actividad racional. Cualquiera que sea, la filosofía no puede renunciar, a menos que renuncie a su propia naturaleza, al ejercicio de la razón. Esto es lo que la distingue del mito o la religión. E incluso cuando una filosofía como la tomista se plantea problemas que, según la Teología, Dios revela al hombre, sólo se vuelven filosóficos cuando se echa mano de la razón para tratar de esclarecer lo revelado por la fe. Y cuando, en nuestro tiempo, se ataca - a la razón-, lo que se ataca en definitiva es una forma histórica de ella - la Razón ilustrada- o cierto uso tecnológico o instrumental de la razón, y aún para desencadenar este ataque, el filósofo - posmoderno o francfortiano- no puede prescindir de la razón.

\section{III}

La filosofía aborda, pues, por la vía racional, los problemas que plantea a los hombres su relación con el mundo, y entre sí. Su terreno propio es, pues, la explicación, argumentación o interpretación racional. Históricamente, sus respuestas racionales se integran con otras en un todo o en un sistema. Pero también da respuestas que generan nuevas preguntas que no permiten cerrar el sistema. En la filosofía en cuestión pueden pesar más las preguntas que las respuestas, los interrogantes que las afirmaciones.

Vemos, pues, que la búsqueda que surge de la duda, de la inseguridad, conduce unas veces al cierre de la problematicidad, asegurando así cierta armonía o concordancia con el mundo, y otras a una discordancia e insatisfacción de la que nace una aspiración a transformarlo, a llegar a lo que no es todavía o debe ser. El tomismo, el racionalismo leibniziano, el idealismo absoluto de Hegel, o el positivismo clásico, podrian ejemplificar lo primero; Kant, Kierkegaard, Marx o Habermas, lo segundo.

Ahora bien, tanto en un caso como en otro, ya sea que se ponga el acento en lo que es, o en lo que no es todavia y debe ser, la filosofia es asunto de la razón, actividad teórica $\longrightarrow$ interpretación - con la que el hombre responde a la necesidad vital de entender el mundo para orientar su comportamiento en él. Tal es la filosofía sin más : la que responde con conceptos y transformando conceptos; es decir, como teoría, a las cuestiones fundamentales que planteaba Kant. Por ello, aunque comparta un espacio 
común, por su problemática, con otras actividades -mito, religión o arte-, lo que hace de ella una actividad propia, incluso cuando aborda problemas comunes con ellas, es lo que tiene de interpretación fundada en argumentos racionales acerca del conocimiento, sobre lo que debe ser y acerca del sujeto - el hombre- que se plantea las cuestiones correspondientes. La filosofía lo es sin más en cuanto que las aborda en la esfera del concepto, de la razón.

\section{IV}

Podría pensarse en un más, o más allá de la filosofía, si trascendiendo su esfera propia, como actividad teórica, racional, se convierte, o pretende convertirse, en otra actividad: estética, moral, política o práctica (en el sentido de "praxis"). La historia de la filosofia ha sido hasta ahora, y pensamos que seguirá siéndolo, su historia como interpretación, o sea: como un cuestionar y dar razón de todo lo que cuestiona. Eso ha sido para Marx la historia de la filosofía, cuando en su Tesis x sobre Feuerbach dice: "Los filósofos se han limitado hasta ahora a interpretar el mundo". Con ello, no está postulando que haya que renunciar a dar razones del mundo, a interpretar. O sea: que se renuncie a la filosofia sin más. Pero, chay acaso un otro o más de ella que pudiera aceptarse? Ese más podría consistir, tal vez, en el abandono de su esfera propia, teórica, para convertirse en práctica, entendida ésta como actividad efectiva, transformadora, que hace emerger de lo dado, de lo existente, una nueva realidad (como sucede con el arte, el trabajo o la política).

Pero, en cuanto teoría o interpretación, la filosofía no es práctica en este sentido. No cambia o transforma de por sí el mundo. Una cosa es pensarlo, y otra, transformarlo. Insistimos: la filosofía sin más es cosa del pensamiento, de la razón: trátese de lo que es, o de lo que no siendo aún, se aspira a que sea porque debe ser. Ahora bien, considerar que la filosofia es este más de la práctica, o que - de por sí, en su esfera propia - sea práctica, ¿significa acaso que no tenga nada que ver con el comportamiento práctico y que, por tanto, ese sin más haya de entenderse como un límite que la pone a extramuros de ese comportamiento?

Recordemos que en su Tesis xi Marx no está reprochando a los filósofos que su actividad sea interpretación, sino que se limiten a ella, o más exactamente que la reduzcan a cierta interpretación. Veamos, más detenidamente, esta cuestión, que no es otra que la de la relación entre la teoría y la práctica (en este caso: la filosofia). Su modo de relación el de la filosofía - con la práctica tiene dos caras. La primera se muestra en sus efectos prácticos. Por el hecho mismo de expresar una relación 
con el mundo, de ser el hombre el objeto y sujeto de ella, toda filosofía no deja de tener efectos prácticos. Por ello, el Estado en una sociedad dada o la sociedad misma, o determinados sectores o clases sociales, apelan a cierta filosofía para fundar o legitimar, con razones, la conservación, reforma o transformación de cierto mundo humano. No se podrían negar en ese sentido los efectos prácticos de filosofias como las de Platón, Tomás de Aquino, Diderot, Rousseau, Kant, Hegel, Marx o Sartre en los hombres de su tiempo. Incluso las filosofias pesimistas - como la de Schopenhauer - que invitan a la inacción, o las posmodernas de hoy que privan de fundamento a toda empresa de emancipación no dejan de tener efectos prácticos.

Esta irrupción de la filosofía en la práctica por los efectos que en ella tiene, no contradice nuestra tesis anterior de la filosofía sin más como interpretación del mundo, o actividad teórica. Pero siéndolo, y sin dejar de ser tal, y sin asumir el más que significaría su conversión en una práctica real, efectiva, incide en ella al fundarla, justificarla o legitimarla. Un ejemplo elocuente de esto es la filosofía francesa del sigloxvir con su influencia en la Revolución francesa y, más allá de ella, en los movimientos de independencia de América Latina. Y esto es así incluso si los filósofos no se han propuesto ejercerla; es decir, si no han pretendido contribuir, intencionalmente, a la práctica correspondiente. En suma, una filosofía no deja de tener efectos prácticos, aunque se haya limitado -como dice Marx- a interpretar el mundo, desentendiéndose por tanto de sus consecuencias prácticas. Y, por supuesto, aunque el filósofo no haya asumido conscientemente la necesidad de contribuir —con su actividad teóricaa desencadenarlas.

\section{$\mathbf{V}$}

Pero, ¿puede haber filósofos que pretendan saltar ese límite -el de cierta interpretación-, sin que, al saltarlo, su relación con la práctica no se reduzca a los efectos prácticos que el pensar filosófico pueda tener en ella, aun sin buscarlos deliberadamente? La Tesis xI de Marx entraña una respuesta afirmativa a esta cuestión, ya que exhorta a los filósofos a no limitarse a lo que hasta ahora han hecho: interpretar el mundo, entendida la interpretación como un desinterés por sus efectos prácticos. Pero, en verdad, si no se renuncia en este caso a la filosofía sin más como interpretación, sí se renuncia a la interpretación que, al complacerse a sí misma, se presenta como un límite; límite "cuando de lo que se trata - como se dice en la segunda parte de la Tesis citada- es de transformar el mundo". Así, pues, este "no limitarse" en el filosofar, hay que entenderlo no en el 
sentido de hacer de la filosofía lo otro de la teoría, de tal modo que ésta se convierta, de por sí, en práctica. Ahora bien, la filosofía sin más es y sólo es teoría. No se trata, por tanto, de abandonarla en nombre de un activismo o practicismo para darlo todo a la práctica. Cierto es que no falta en política la subjetividad impaciente - como diría Hegel- de quienes pueblan sus sueños revolucionarios con asaltos a Palacios de Invierno al grito de: “ßBasta ya de teoría; es la hora de la práctica, de la acción!”, pero nada más lejos de la Tesis xi de Marx. No, no se trata de eso. Por otra parte, la experiencia histórica, relativamente reciente, de algunos movimientos armados en América Latina, prueba el terrible costo político y humano que ha tenido una práctica, ayuna de teoría.

La filosofía - como hemos subrayado antes- ha tratado de satisfacer por una vía propia, la de la razón, una necesidad vital: orientar al hombre en su relación con el mundo. Y, con sus respuestas, lo afirma en él, o bien lo inquieta, desazona o insatisface aún más. Y es de esta inquietud, discordancia o inconformidad, de la que brota la conciencia de la necesidad de transformar ese mundo y la asunción del deber de contribuir a esa transformación. Y ¿cuál es la aportación del filósofo en cuanto tal? En verdad, no la de todo filósofo, ya que hay los que se sienten cómodos en ese mundo mientras puedan cultivar serenamente su propio jardín, o los que llegan a la conclusión de la irrelevancia o la imposibilidad de esa tarea. Pero, si el filósofo se hace eco de una aspiración - que crece fuera de su propio jardín-, de los hombres sencillos y corrientes, de que el mundo no está bien hecho, de que no se vive en el mejor de los mundos posibles, y de que el presente, real, ha de ser transformado, su deber es contribuir a ello. ¿Cómo? Por supuesto, el filósofo es un hombre de "carne y hueso", y nada puede impedirle participar - como cualquier ciudadano- en la actividad práctica para transformarlo. Ahora bien, como filósofo, su contribución está en hacer uso del arma teórica de que dispone: la filosofía — sin dejar de ser teoríaen el proceso práctico de transformación. Lo cual significa no limitarse a una interpretación que se desentiende de sus efectos prácticos, acogiéndose a la idea de una supuesta "neutralidad ideológica". Éste - y no otro- es el sentido de la segunda parte de la Tesis xI de Marx cuando dice: "De lo que se trata es de transformar el mundo". Si de esto se trata, la filosofía - y tal es su mensaje- no puede limitarse a interpretar, a dar razón de lo que es, sino también a trazar las posibilidades, la utopía, de lo que no siendo aún, puede y debe ser. Y ha de contribuir a ello, abriéndose paso entre el Escila y Caribdis del teoricismo y el practicismo; es decir, como filosofía sin más, como teoría que sin ser de por sí práctica, cumple una función práctica, vital. 


\section{VI}

Pero, el más de la filosofía, aquello que la saca de su terreno propio, no sólo le llega por el lado de la práctica, al hacer de la teoría -como pensaban los jóvenes hegelianos- una práctica que, con el poder de la razón, pudiera destruir la irracionalidad de la realidad misma, sino también cuando la teoría, sin descender del cielo en que reina, se convierte en reina también aquí en la tierra como norma, modelo o ley de la práctica. No se trata sólo de los efectos prácticos que puede tener, sino de normar, modelar o sujetar la práctica desde su esfera propia: como idea, teoría o pensar auténtico. En la historia de la filosofía no escasean los ejemplos del poder decisorio que se le atribuye en la conformación de lo real. Nos remitiremos a tres, en los que se pone de manifiesto semejante relación entre idea y realidad, o.entre teoría y práctica.

El primero de ellos es el de la filosofía política de Platón con su concepción del Rey-filósofo en La República. Los problemas de la comunidad sólo serán resueltos, a juicio suyo, cuando los filósofos sean reyes o cuando el gobierno de la ciudad esté en sus manos. El más de la filosofía consiste aquí en el poder del filósofo, legitimado - no democráticamente-, sino por el privilegio epistemológico de que goza en cuanto al conocimiento del Estado ideal, o de lo que la comunidad debe ser. El imperio de la filosofía se extiende a la realidad empírica, ya que ésta se halla sujeta - como sombra de la Idea- a la comunidad ideal.

Un segundo ejemplo, contemporáneo, es el de la versión marxista, o seudomarxista, que bajo el rubro de "marxismo-leninismo" se ha derrumbado en nuestra época con el sistema autoritario, burocrático que pretendió conformar, en todos sus aspectos, lo real. Se trata de un nuevo platonismo. Aquí el Rey-filósofo no es un hombre, sino el Partido que se proclama detentador único y exclusivo de la verdad y del secreto de la historia, y, por tanto, el único que puede dirigir a la sociedad en la tarea de construir una nueva realidad social -el socialismo- conforme a la visión que tiene de ella. De este modo, lejos de fundarse en la práctica, la teoría se convierte en la ideología de una nueva clase social: la burocracia, que la legitima y justifica. Como en la filosofía platónica, el nuevo Reyfilósofo, el Partido, legitima su papel de vanguardia, de dirigente, por el privilegio epistemológico de ser el depositario de una verdad que sólo él puede llevar a las masas.

El tercer ejemplo, también contemporáneo, es el de Heidegger. No quiero abordar ahora una cuestión digna de ser contemplada: la de la relación posible o real, imaginaria o efectiva entre su nazismo militante y su ontología fundamental. Me referiré exclusivamente al filósofo "de carne 
y hueso", Martin Heidegger, quien, como Rector de la Universidad de Friburgo y con la credencial del Partido Nazi en el bolsillo, establece -en su célebre discurso de mayo de 1933 - una estrecha vinculación entre el nazismo y la política universitaria alemana, a partir de varios presupuestos de su filosofía. Con base en ellos y arropado con el enorme prestigio y la autoridad que ha conquistado desde Ser y tiempo, con su filosofia, Heidegger se presenta como el guía, conductor o Fübrer, en la tarea - como una exigencia que él plantea- de vincular la Universidad a la nación alemana, o más exactamente a la política nazi. Así, pues, atendiéndonos a su famoso Discurso del rectorado, podemos decir que en él se pone de manifiesto la concepción, de raigambre platónica, del filósofo como Rey o Fühner por su acceso privilegiado a la verdad o al Ser. Estamos, pues, en el caso del Discurso citado, ante el filósofo que pretende conducir o dirigir una práctica política desde su posición epistemológica privilegiada, llevándola más allá - por su conversión en práctica- de lo que como teoría puede dar.

\section{VII}

El más de la filosofía no sólo puede aparecer en esta relación con la práctica, sino también al ampliar desmesuradamente su propio espacio teórico hasta el punto de pretender disolver en él la propia realidad. Este más de la filosofia como sistema total, omnicomprensivo y cerrado, lo ejemplifica cabalmente el idealismo o racionalismo absoluto de Hegel y, en mayor o menor grado, los diferentes sistemas especulativos, metafisicos, que constituyen verdaderas catedrales del pensamiento en las que se pretende comprender o encerrar todo lo existente. Se trata de macrofilosofias en las que la relación del hombre con el mundo se disuelve, o se vuelve secundaria con respecto al principio universal, supremo, que todo lo rige, llámese Dios, Idea, Espíritu o Materia.

El más de la filosofía aparece también cuando al privilegio epistemológico que se le atribuye con respecto a la verdad, se añade el que se atribuye a sí misma al erigirse en instancia suprema o juez en la esfera del conocimiento. Sucede lo primero cuando se presenta —n el positivismo clásico- como síntesis o supersaber que unifica los conocimientos de las diferentes ciencias, lo que hace de ella la Ciencia de las ciencias. Y lo segundo acontece cuando se considera como un saber fundamental que la convierte en el juez que fija los límites entre ciencia e ideología. O como dice Althusser: "La filosofia tiene por función principal trazar líneas de demarcación entre lo ideológico de las ideologías, y lo científico de las ciencias". Esta misión judicial o purificadora de la filosofia, si bien no hace de 
ella -como hace el positivismo- la Ciencia de las ciencias, puesto que no las sustituye en la producción de conocimientos, sí la erige en el juez que hace saber a los científicos lo que, al parecer, ellos no saben: lo que es propiamente científico. Sin negar la aportación que la filosofía puede prestar al desentrañar el concepto de verdad, o al esclarecer el proceso de conocimiento, tarea que como hemos señalado antes corresponde a la filosofía sin más, se rebasa este más cuando se atribuye a sí misma el privilegio de dar al científico la conciencia de su propia práctica, o de salvarlo de las acechanzas de la ideología, como si el hombre de ciencia estuviera condenado a la inconsciencia o espontaneidad en su trabajo científico. Pero esta especie de imperialismo filosófico que lleva a la filosofia a extender sus fronteras, lo hallamos también cuando pretende proporcionar el fundamento último de todo sector de la cultura: la ciencia, el arte, la política o la técnica, lo que le daría el derecho o el nuevo privilegio, ontológico, de distribuir el lugar que deben ocupar cada uno de esos sectores, así como el de reconocer cuál de ellos es preeminente en una cultura dada. Ahora bien, el lugar dominante que ocupan la política, por ejemplo, en la antigua sociedad griega; la religión, en la Edad Media, feudal, o la economía en la sociedad capitalista contemporánea, no lo fija la filosofía, sino las relaciones sociales, de clase, correspondientes. Y ellas son, asimismo, las que se encargan de fijar el lugar que la filosofia ocupa en la cultura de la sociedad y la época de que se trate.

\section{VIII}

Hasta ahora nos hemos detenido en lo que, a nuestro juicio, constituye lo otro, o el más de la filosofía, al concebirse: como práctica de por sí; como norma o modelo que determina a la práctica; como sistema absoluto que engloba tanto a la idea como a la realidad, y, finalmente, cuando se erige en juez de la ciencia, o fundamento último de todo sector de la cultura. Pero la filosofia no sólo se atribuye a veces más, sino también menos de lo que le corresponde o puede dar. Si antes la hemos visto con este más que la coloca en una posición privilegiada, imperial, ahora la veremos con un menos que la empequeñece, angosta o estrecha. Así sucede cuando la filosofia se reduce -como la reducía Carnap en los años treintas, a una "rama de la lógica", lo que equivalía a liquidarla, si se acepta la tesis de que, en rigor, la filosofía es ciencia y no propiamente filosofía. Pero, aun aceptándola como tal, si queda reducida a la lógica, ¿qué pensar entonces del hecho cultural, histórico, de que unos hombres, llamados filósofos, se hayan ocupado durante siglos del mundo, del hombre, de la historia, de los valores, etcétera? Los filósofos que se han planteado estos 
problemas "tradicionales" con la pretensión de resolverlos, lo han hecho utilizando un lenguaje que se distanciaba de la "sintaxis lógica" o de su uso "lógicamente correcto". De ahí la inconsistencia de su planteamiento y de sus soluciones. Es, pues, la lógica, supuestamente neutral, la llamada a decidir el destino de esos problemas filosóficos al reducirlos a problemas de lenguaje, meramente verbales o carentes de significado.

La idea de que los problemas filosóficos tradicionales, sustantivos, tienen su caldo de cultivo en un uso incorrecto del lenguaje y que, por tanto, su uso adecuado conduce a la "disolución" de esos problemas, es también bandera de una filosofía posterior: la filosofía analítica. Pero en ésta no se trata del lenguaje ideal, lógico, sino del lenguaje ordinario. Si en Camap, el "uso incorrecto" lo es con respecto a la "forma lógica" del lenguaje, en la filosofía analítica la "incorrección" se da en relación con la "gramática ordinaria" de un lenguaje dado. Pero, con respecto a un caso como a otro, ha objetado Rorty, la falta de criterios para analizar el concepto de "significado", y por tanto, para establecer el significado de "análisis" y de "análisis correcto" del lenguaje, ya se trate del lenguaje lógico o del ordinario. ¿Con qué base se puede pretender, entonces, reducir tan desmesuradamente el campo de la filosofia, y expulsar de él los problemas que responden, en definitiva, a una necesidad vital, humana? Pero esta "disolución" de los problemas filosóficos tradicionales o sustantivos no sólo puede objetarse -como hace Rorty - por la falta de criterios de significado necesarios para llevar a cabo esa "disolución", sino también porque presupone tesis filosóficas sustantivas que pugna por disolver. Así, por ejemplo, si la filosofía es una actividad humana que se ocupa del lenguaje con el que los hombres hablan a otros hombres de religión, arte, política, etcétera, se presupone una naturaleza humana en la que se inscribe esencialmente la función comunicativa. Hablar - al igual que pensar y actuar prácticamente- son actividades humanas. Por una necesidad no sólo teórica, sino práctica, vital, la filosofia no puede dejar de plantearse el problema sustantivo, de la naturaleza del hombre, que sólo lo es como ser pensante, comunicativo y práctico. Se hace, pues, insostenible tratar de "disolver" este problema, como otros también fundamentales, y reducir la tarea del filósofo al análisis del uso del lenguaje, ya sea éste el lógico o el ordinario.

\section{IX}

Semejante estreñimiento de la filosofía se da también cuando, a partir del reconocimiento de su componente ideológico, en cuanto que no puede sustraerse a los intereses sociales o de clase de su tiempo, al expresarlos deja a un lado su filo crítico y cognoscitivo y se reduce a ese componente. 
La teoría se convierte entonces en simple ideología, destinada a legitimar las relaciones de dommación o explotación existentes. Una filosofía de la historia como la que, por ejemplo, ha propuesto en nuestros dias Fukuyama, con su tesis del "fin de la historia", es pura ideología en cuanto que su interpretación de los grandes acontecimientos de nuestro tiempo - la derrota del nazismo y el hundimiento del "socialismo real" - sólo le sirve para justificar la existencia sin fin del capitalismo liberal.

Pero esta filosofía que sacrifica su relación con la verdad en el altar de la ideología, no sólo se da al pugnar abiertamente - como la del neoliberalismo- por conservar eternamente el mundo como es (el mundo de la explotación y la opresión), sino también se ha dado en filosofías que se vinculan a una práctica de emancipación y liberación. Así sucede con cierta versión de la filosofía latinoamericana en nuestros días. Aunque en América Latina la filosofía puede y debe contribuir a elevar la conciencia de la identidad del hombre latinoamericano, del sentido de su historia y de sus posibilidades de emancipación, objetivo que entraña filosofar desde la circunstancia latinoamericana, esto no significa que para hacer tal filosofia haya que latinoamericanizar o dar un color continental a categorías filosóficas como las de verdad, enajenación, contradicción, etcétera. No se trata de sacrificar lo que es válido teórica o universalmente a las exigencias de la ideología. Filosofar en América Latina es, en este sentido, como dice Leopoldo Zea, poner en relación las ideas y la realidad; o como él dice también: filosofar sin más, y yo agregaría, ni menos.

Otro ejemplo de una filosofía de emancipación que, por exigencias ideológicas, se reduce hasta convertirse en simple ideología, es la que, en nombre de Marx, ha dominado - como "marxismo-leninismo" - hasta el derrumbe en el Este europeo del llamado "socialismo real". Con su metafisica materialista o "materialismo dialéctico" y su concepción lineal, determinista y teleológica de la historia, se convirtió en la justificación de un nuevo sistema de dominación y explotación y en la legitimación del poder de la burocracia estatal y del Partido. Es decir, en la ideología de una nueva clase. El menos de la filosofía se reduce aquí a tal grado, ante el avasallamiento de la ideología, que aquélla prácticamente desaparece.

\section{$\mathbf{X}$}

Llegamos al final de nuestra exposición. Hemos dicho que la filosofía responde a la necesidad vital de esclarecer el puesto del hombre en el mundo, contribuyendo así a mantenerlo, reformarlo o transformarlo. Esta necesidad vital se vuelve hoy imperiosa en un mundo en el que la violencia desafia a la razón; en el que la vida cotidiana conoce nuevas formas 
de enajenación y colonización de las conciencias; en que predominan los valores hedonistas, consumistas; en que el progreso científico y tecnológico se vuelve contra el hombre y en el que, no obstante el desarrollo económico, técnico y social de un grupo de países, la mayoría de los individuos y los pueblos sólo conocen la explotación, la miseria y la marginación. En este mundo, la filosofía se hace necesaria para contribuir a hacer más racionales y humanas las relaciones entre los hombres y los pueblos. Pero ¿qué filosofia? Por lo pronto, la filosofía sin más ni menos. 